\title{
Ocupar o centro: Vivências no processo de reconversão de imóveis abandonados em áreas centrais
}

\author{
Andressa de Luca Heredia de Sá \\ Mestranda em Planejamento Urbano e Desenvolvimento Sustentável, Planning for the Urban Agenda, no Politecnico \\ di Torino (PoliTo). \\ Contato: andressadeluca@gmail.com
}

\section{RESUMO}

Esta pesquisa surge da crítica ao Programa Minha Casa Minha Vida (PMCMV) frente à disponibilidade de imóveis vacantes nos centros urbanos. O trabalho parte de estudos teóricos e empíricos que propõem uma reflexão, através de diferentes abordagens metodológicas, para a realização da reconversão de imóveis abandonados na área central. Questiona também o papel dos profissionais e estudantes de arquitetura na prestação de assessoria técnica de movimentos populares. A Ocupação Vito Giannotti (OVG), localizada no Bairro do Santo Cristo, na área portuária da cidade do Rio de Janeiro, foi definida como estudo de caso visando demonstrar a importância do projeto participativo para alcançar um ambiente construído de qualidade. Essa experiência demonstra a necessidade de formar arquitetos com a capacidade de interlocução e mediação, em vez da imposição do projeto arquitetônico.

Palavras-chave: Assessoria Técnica; autogestão habitacional; Ocupação Vito Giannotti.

\section{Occupying the Center: Experiences in the process of converting abandoned real estate located in central areas}

\begin{abstract}
This research emerges from the critique of the Programa Minha Casa Minha Vida (PMCMV) considering the availability of vacant properties in urban centers. The work begins with theoretical and empirical studies that propose a reflection, through the different methodological approaches, to carry out the conversion of abandoned properties in the central areas of large cities. It also questions the role of architecture professionals and students in providing technical assistance to popular movements. The Ocupação Vito Giannotti (OVG), located in the Santo Cristo neighborhood, in the port area of the city of Rio de Janeiro, was defined as a case study aiming to demonstrate the importance of the participatory project to achieve a built environment of quality. This experience demonstrates the need to train architects with the capacity to dialogue and mediate, instead of imposing the architectural project.
\end{abstract}

Keywords: Technical Assistance; Social Housing Self-Management; Vito Giannotti Occupation. 


\section{Introdução}

O objetivo deste trabalho é ilustrar como o envolvimento com assessoramento técnico pode contribuir para a formação de profissionais de arquitetura capacitados a elaborar soluções para mitigar o problema do déficit habitacional. Ao trabalhar com proximidade a ocupações de imóveis abandonados, esta pesquisa ilustra parte do processo de reconversão desses imóveis em moradia. Como princípio, considera-se que a assessoria técnica seja um método capaz de produzir espaços mais adequados às necessidades da população que os tradicionalmente oferecidos pelo mercado imobiliário e os programas públicos habitacionais.

A partir de estudos teóricos e experiências empíricas, propõe-se uma reflexão sobre o papel da Arquitetura nesse contexto por meio de diferentes metodologias: visitas e entrevistas em duas ocupações e dois conjuntos habitacionais - o Jardim Edite (2010) e o Conjunto Heliópolis (2011), localizados em São Paulo; mapeamento histórico de ocupações de imóveis ociosos na área central do Rio de Janeiro; e trabalho de campo com assessoria técnica na Ocupação Vito Giannotti, no Centro do Rio de Janeiro, entre o período de junho a dezembro de 2019.

No caso do Rio de Janeiro, a realização da assessoria técnica em parceria com escolas de arquitetura demonstra como esse processo pode contribuir com o ensino de arquitetura e vice-versa. Os benefícios observados incluem a oportunidade de tratar do tema do déficit habitacional e da autogestão de forma prática e o maior suporte aos movimentos de luta por moradia, que acaba por acelerar o processo de desenvolvimento projetual.

As visitas e entrevistas foram realizadas em conjuntos habitacionais, projetados durante a Operação Urbana Consorciada Água Espraiada (OUCAE) ${ }^{1}$ e financiados através do Programa Minha Casa Minha Vida (PMCMV), e em ocupações beneficiadas pelo PMCMV-Entidades, objeto de estudo principal deste trabalho. Esses dois métodos possibilitaram avaliar os benefícios do projeto participativo em comparação ao projeto padrão de Habitação de Interesse Social, no qual não há participação dos residentes durante as decisões de projeto.

Tal metodologia possibilitou o entendimento das necessidades dos moradores, demonstrando que variam de acordo com desejos relacionados ao contexto que estão inseridos. Por exemplo, durante a visita e as entrevistas com os mora- dores do Conjunto Heliópolis, ainda que estivessem satisfeitos com a flexibilidade do layout das unidades e com a acessibilidade, os moradores apontaram a necessidade da criação de espaços de lazer infantis e uma biblioteca coletiva, não previstos no projeto, ainda que já se configurassem em uma demanda dos moradores por não haver espaços semelhantes no entorno.

Além das visitas e entrevistas, a experiência in loco também permitiu a compreensão das necessidades e demandas dos estudos de caso em cada contexto urbano, sendo possí-

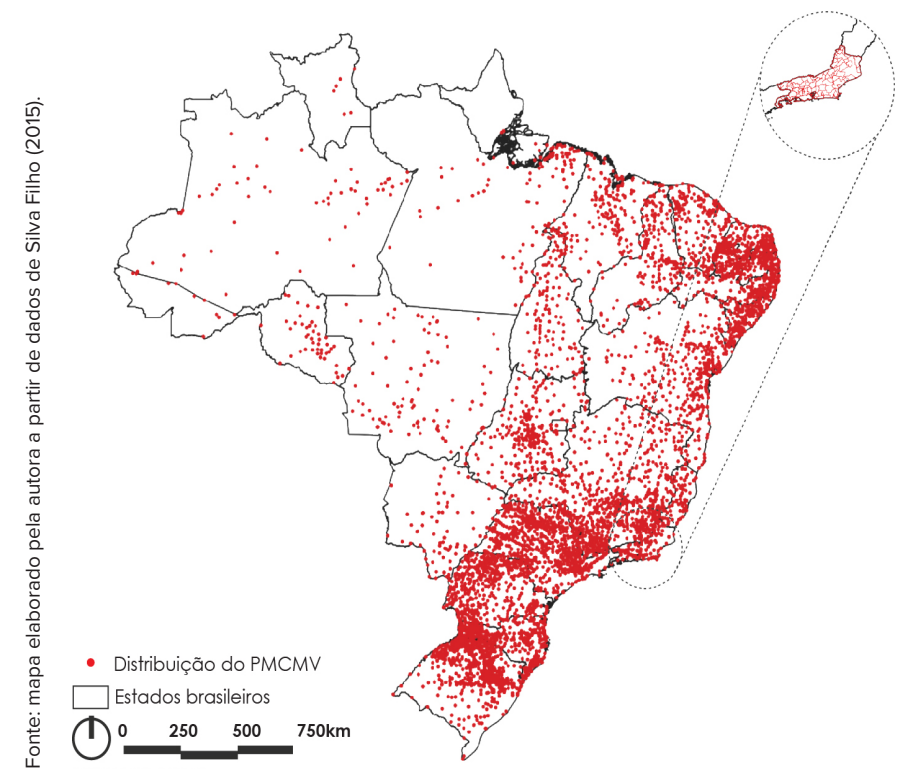

Figura 1. Distribuição de unidades do Programa Minha Casa Minha Vida no Brasil, 2019. Os dados demonstram a alta demanda por moradia social nas grandes cidades e concentração do programa nas capitais do litoral brasileiro.

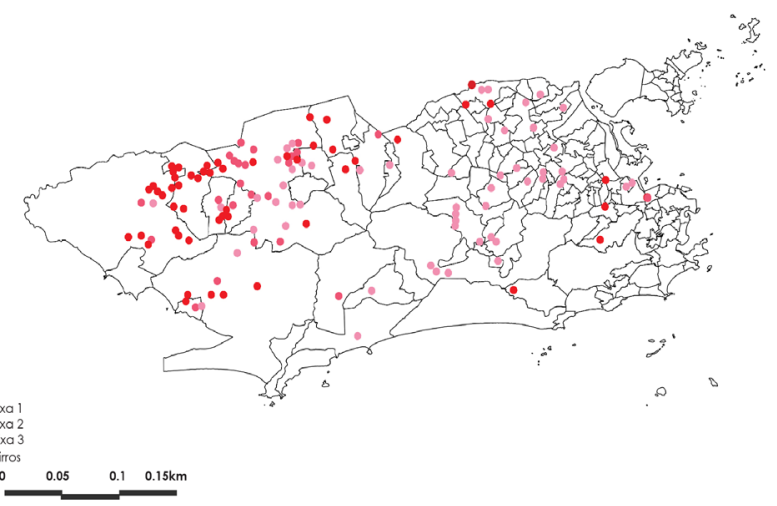

Figura 2. Distribuição de unidades do Programa Minha Casa Minha Vida na cidade do Rio de Janeiro, 2019. Os dados indicam a concentração das faixas para famílias com menores rendas na zona oeste, longe dos postos de trabalho, transporte público e centro da cidade. Além disso, é possível notar a concentração do programa apenas nas zonas norte e oeste da cidade. 


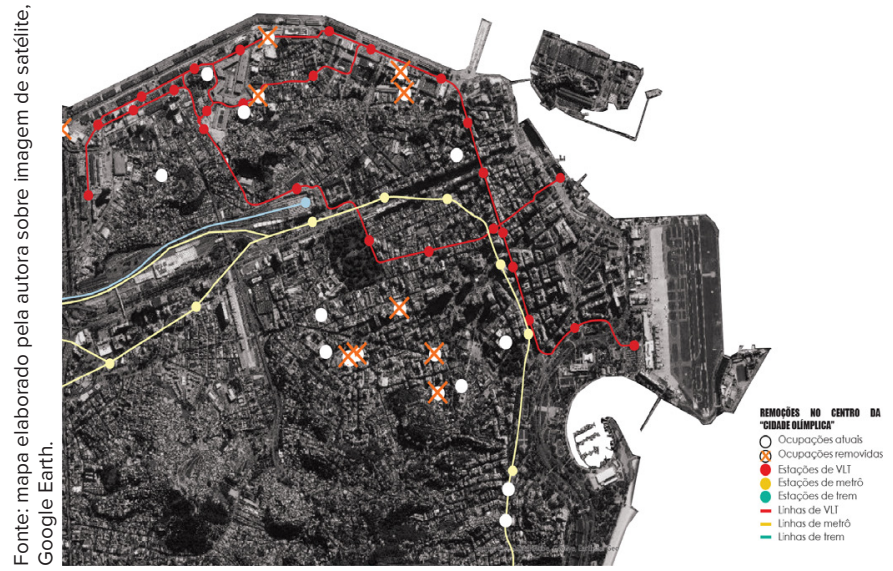

Figura 3. Mapeamento de remoções de ocupações dos movimentos de luta por moradia no Centro do Rio de Janeiro, 2019.

vel notar as especificidades de cada um. É válido ressaltar também que a própria experiência relatada se estabelece como um importante fator para apresentar os métodos de execução do projeto participativo, que se baseia no contato com as pessoas, moradores e usuários do espaço a ser projetado, buscando atender suas demandas e interesses.

Segundo Arno Vogel e Marco Antônio Mello (1983), quem produz o espaço é, de certa forma, aquele que o vivencia. Sendo assim, as práticas sociais são capazes de definir os usos variados do espaço urbano. Logo, pode-se afirmar que, à medida em que os projetos participativos possibilitam o maior envolvimento dos usuários do espaço nas decisões, proporcionam também uma aproximação maior do projetista com uma dimensão mais pessoal e sutil do projeto.

A noção de lar se estende muito além de sua essência e de seus limites físicos. Além dos aspectos práticos de residir, o ato de habitar é também um ato simbólico que, imperceptivelmente, organiza todo o mundo do habitante. Não apenas nossos corpos e necessidades físicas, mas também nossas mentes, memórias, sonhos e desejos devem ser acomodados e habitados. Habitar é parte do nosso próprio ser, da nossa identidade. (PALLASMAA, 2017, p. 8)

O Conjunto Habitacional Jardim Edite, projetado por $\mathrm{H}+\mathrm{F}$ e MMBB Arquitetos em 2010, por exemplo, conta com equipamentos públicos em seu pavimento térreo, como creche e Unidade Básica de Saúde. Anteriormente, existia no local uma comunidade que havia se estabelecido nessa região pela proximidade com o trabalho, mas foi propositalmente incendiada para que fosse removida do local. Com isso, o projeto do conjunto habitacional foi eficaz por realocar as famílias que já residiam no bairro e a localização era um fator importante para as mesmas.

Já o Conjunto Heliópolis Gleba G, projetado por Biselli Katchborian Arquitetos em 2011, afastado da zona central da cidade de São Paulo em região carente de áreas públicas, conta com espaços de lazer compartilhados entre os moradores e com uma implantação horizontalizada -450 unidades de $5 \mathrm{Om}^{2}$ e unidades térreas para Portadores de Necessidades Especiais (PNE). Além disso, seus usuários apresentaram a demanda de espaços de trabalho dentro do conjunto habitacional e, por isso, foram previstas unidades com layout flexível para compor pequenos espaços de trabalho - tais como estúdio de fotografia, espaço de confeitaria e de costura. Segundo os moradores do Conjunto Heliópolis, o projeto foi eficaz, no sentido de ter sido implementado no mesmo local de remoção das famílias, por possuir unidades com layout flexível e, ainda, por contar com espaços comerciais voltados para a rua.

\section{Contexto Histórico da Habitação no Rio de Janeiro}

Historicamente, a região central da cidade do Rio de Janeiro, como a maioria dos centros urbanos, foi o local onde a população carioca se concentrou e a partir do qual se expandiu. No decorrer do século XVII, a ocupação urbana começou a se estender para além do entorno do Morro do Castelo, um dos primeiros pontos ocupados da cidade no período colonial. Já durante o século XIX, com o fim da escravidão, a chegada das indústrias e o elevado crescimento populacional - ocasionado pela grande migração à capital em busca de emprego e de melhores condições de vida - , a região passou por importantes mudanças. Dessas transformações, as mais importantes se caracterizam como uma série de obras para a expansão da malha urbana, como o desmonte de morros, aterramentos e a canalização de rios, com o objetivo de comportar o processo de industrialização e o fenômeno migratório.

A princípio, a localização geográfica, a infraestrutura e a proximidade com os polos de trabalho tornaram o centro uma região atrativa para moradia. Entretanto, a disponibilidade de imóveis não acompanhou a demanda, gerando forte inflação, especulação imobiliária e o surgimento de cortiços (ABREU, 2013) - unidades utilizadas como habitação coletiva compostas de vários cômodos e com superlotação de pessoas em um mesmo ambiente e baixas condições higiênicas. ${ }^{2}$

Revista online do Departamento de Arquitetura e Urbanismo da Pontifícia Universidade Católica do Rio de Janeiro - PUC-Rio, Brasil Ano 8 - N응 - ISSN 2446-7340 
Esses fatores, característicos das péssimas condições de moradia em que as famílias recém-chegadas foram se instalando, fizeram com que a qualidade sanitária desses locais se agravasse, resultando em um surto de epidemias.

Em 1902, Francisco Pereira Passos assumiu a prefeitura do Rio de Janeiro. Em seu governo, que buscava solucionar os problemas de superlotação, mobilidade e infraestrutura urbana, a disseminação de epidemias foi amenizada pela erradicação dos cortiços e expansão urbana baseada em justificativas sanitaristas. Nesse cenário, a capital passou a receber mais investimentos para infraestrutura e ampliação da malha urbana.

Em 1927, durante a administração do prefeito Caio Prado Júnior e a elaboração do Plano Agache de remodelação urbana, diversas leis foram criadas para "embelezar" a cidade de acordo com critérios funcionais e de estratificação social do espaço.

A necessidade de controlar o processo de reprodução da força de trabalho, que assegurava também a separação espacial das classes sociais preconizada no Plano Agache, aparecia com bastante clareza na análise que seu autor fazia das favelas. O plano foi o primeiro documento oficial a tratar explicitamente delas, tidas como uma nova forma de habitação popular e um problema social e estético para o qual só havia uma solução - sua erradicação. (ABREU, 2013, p. 87)

A erradicação das favelas, por meio de desapropriações e realocações, e as propostas relativas aos subúrbios, como a criação de vilas operárias dispostas de melhores condições higiênicas, faziam parte de uma estratégia de intervenção do Estado para a adoção de políticas setoriais. Com uma política hostil a habitações informais, o uso residencial do centro da cidade foi desaparecendo gradativamente.

Entre os efeitos do Plano Agache estão o déficit habitacional da região central da cidade e os vazios urbanos. A sugestão de Alfred Agache, responsável pelo Plano, foi a de que o Poder Público impedisse a construção estável nas favelas e transformasse os Morros da Conceição, da Providência e do Pinto em vilas de residência para funcionários e pequenos comerciários. Agache também encorajou a construção de grandes avenidas, o planejamento do transporte de massas e a criação da habitação operária em terrenos mais afastados da área central da cidade.

Embora não tenha sido inteiramente aplicado, o Plano Agache serviu de inspiração por décadas para outros planos diretores da cidade em administrações posteriores. Até mesmo o Programa Minha Casa Minha Vida (PMCMV), criado em $2009^{3}$ como resposta ao déficit habitacional brasileiro e a sua adoção nacional como política pública de habitação, seguiu a lógica de ocupações em terrenos cedidos pela administração pública afastados do Centro. ${ }^{4}$ Além disso, reproduziu o padrão construtivo de baixo custo, baixa qualidade arquitetônica e padronização de soluções pelas construtoras.

Ao longo de sua implementação, o Programa Minha Casa Minha Vida gerou uma série de críticas a respeito da localização, da qualidade arquitetônica e da infraestrutura urbana das unidades habitacionais. Essas críticas foram feitas por arquitetos e urbanistas tais como Nabil Bonduki, Ermínia Maricato e, principalmente, Raquel Rolnik, que, em seu livro de 2015 intitulado Guerra dos Lugares, relaciona a "financeirização" da moradia social no Brasil com incentivos econômicos para beneficiamento das grandes construtoras: "A transferência ideológica da responsabilidade de prover habitação para o mercado foi hegemônica e o paradigma da "casa própria” transformou-se em modelo praticamente único da política habitacional" (ROLNIK, 2015, p. 38).

Para resolver o déficit habitacional nos grandes centros urbanos, que tem sido negligenciado pelo governo brasileiro em suas políticas públicas, a população passou a se organizar em "movimentos de moradia" com a intenção de pressionar a administração pública para a criação de políticas de conversão de prédios vazios, localizados em áreas centrais, em prédios residências. Mesmo com um déficit habitacional na ordem de 220 mil moradias (FUNDAÇÃO JOÃO PINHEIRO, 2018), ainda no final da segunda década do século XXI, o Rio de Janeiro possui cerca de 300 prédios abandonados só no Centro (BIANCA.LOBIANCO, on-line). Parte deles se encontra nessas condições desde a década de 60 , devido à transferência da capital da República para Brasília. Portanto, as ocupações organizadas pelos movimentos de moradia são alternativas metodológicas para o desenvolvimento de projetos de arquitetura no âmbito da habitação de interesse social e uma forma de demonstrar à opinião pública a existência de um sério problema de moradia e de reivindicar o direito à cidade.

Revista online do Departamento de Arquitetura e Urbanismo da Pontifícia Universidade Católica do Rio de Janeiro - PUC-Rio, Brasil Ano 8 - N응 - ISSN 2446-7340 
Segundo Thiago Bastos (2019), a ocupação é uma forma de enfrentamento direto ao cumprimento da função social da propriedade, e que deve ser retomada pela classe trabalhadora através de marcos jurídicos ou não. Os movimentos de luta por moradia não ocupam imóveis abandonados apenas com o objetivo de permanecer nesses edifícios, mas também como forma de denunciar a existência do déficit habitacional e pressionar o poder público para que os direitos à cidade e à moradia adequada para todos sejam garantidos.

Sensível a esse cenário, também em 2009, no âmbito do Programa Minha Casa, Minha Vida, o governo Lula lançou o Programa Minha Casa Minha Vida - Entidades (PMCMV-Entidades) (CAIXA ECONÔMICA FEDERAL, on-line), com o objetivo de tornar a moradia acessível às famílias organizadas por meio de cooperativas habitacionais, associações e demais entidades privadas sem fins lucrativos.

O PMCMV-Entidades estimula o cooperativismo e a participação da população como protagonista na solução de seus problemas habitacionais. De acordo com a regulamentação do subprograma (CONSELHO CURADOR DO FUNDO DE DESENVOLVIMENTO SOCIAL, 2009), as famílias devem possuir renda mensal bruta de até $\mathrm{R} \$ 1.600,00$ e a entidade deve estar habilitada pelo Ministério das Cidades para participar. Por outro lado, o subprograma acaba por demandar burocracias que tornam o processo de contratação junto à Caixa Econômica Federal (CEF) demasiado lento para a urgência de moradia digna das famílias que o demandam, visto que o tempo de espera para a contratação, desenvolvimento e execução projetual pode durar anos.

O Programa é regido pela lógica de injeção de recursos mediados pela CEF e também é co-gerido, de certa forma, por esse agente financeiro operador. Dessa maneira, entendemos que existe uma tentativa de enquadramento por parte do agente financeiro, visando conferir um tom de "pequeno empreendedor" aos movimentos sociais de moradia [...]. Os contratos de financiamento dos "empreendimentos” autogestionários (assim chamados pela CEF) são individuais, ou seja, esses contratos não permitem o reconhecimento da organização popular ali presente. Cada mutuário é responsável pela quitação de seus empréstimos com o banco e, posteriormente, pela sua propriedade individualizada. "Com o lança- mento do MCMV-E vieram novas e extensas exigências da Caixa. O processo de contratação se prolongou por mais tempo" (BASTOS, 2019, p. 24-25, 113).

\section{Estudo de caso: Ocupação Vito Giannotti}

A Ocupação Vito Giannotti se localiza em um edifício no Morro do Pinto, Santo Cristo, Rio de Janeiro. O Morro do Pinto, diferentemente dos morros da Providência e da Pedra Lisa, não é uma favela, sendo ocupado por edifícios institucionais e industriais, tais como o atual centro cultural da Fábrica da Bhering. O imóvel ocupado, que anteriormente pertencia ao Instituto Nacional do Seguro Social (INSS) e havia sido originalmente projetado como um hotel, encontrava-se em estado de abandono desde a década de 1990. Mais tarde, a resolução do INSS/PRES N 21, de 16 de agosto de 2006 (BRASIL, 2006), definiu-o como Habitação de Interesse Social, porém, ainda se manteve vago.

Diante do estabelecimento dessa resolução, os movimentos sociais Movimento de Luta nos Bairros, Vilas e Favelas (MLB), Central de Movimentos Populares (CMP) e União Nacional por Moradia Popular (UNMP) se organizaram para ocupar o edifício e pressionar a reconversão do imóvel em moradia popular durante o Governo Dilma Rousseff (20112016). Com o apoio desses três movimentos, em 15 de janeiro de 2016, 5 a Ocupação Vito Giannotti se articulou na edificação de três pavimentos (térreo, $1^{\mathrm{o}}$ e $2^{\mathrm{o}}$ pavimento e terraço superior).

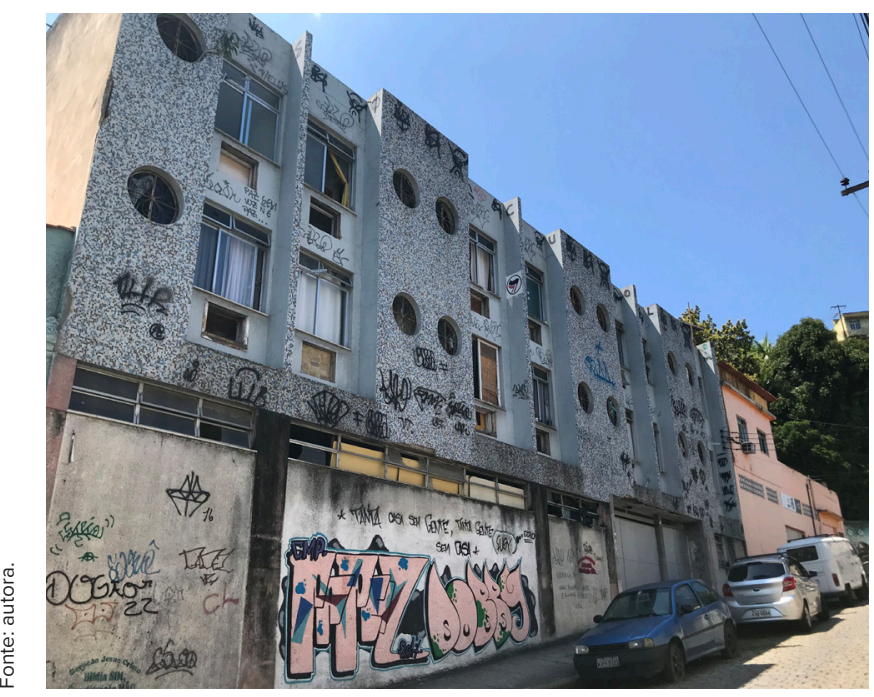

Figura 4. Edifício da Ocupação Vito Giannotti, 2019 
Em 2016, o edifício passou a ter seus espaços ressignificados pelas famílias para atender as necessidades básicas de moradia. Atualmente, aproximadamente 26 famílias com renda bruta familiar entre $\mathrm{R} \$ 0,00$ e $\mathrm{R} \$ 1.800,00$ ocuparam o edifício. Ademais, há uma negociação para a concessão do imóvel entre os moradores e a secretaria da presidência, no gabinete de articulações com movimentos sociais, situado em Brasília. Baseado nessas negociações, os movimentos conquistam a reintegração de posse, impedindo a ordem de despejo de seus moradores.

De acordo com a decisão em segunda instância para renegociação, foi estabelecido o prazo de seis meses para a apresentação de um projeto para o imóvel destinado ao Programa Minha Casa Minha Vida - Entidades. Sendo assim, os movimentos conseguiram avançar com a permanência no edifício, obtendo oficialmente a ligação de água pela Companhia Estadual de Águas e Esgoto do Rio de Janeiro (CEDAE). Foi redigida, então, uma proposta de projeto a ser encaminhada à Caixa Econômica Federal a fim de que a edificação fosse selecionada para o subprograma MCMV-Entidades. No entanto, com o impeachment de Dilma Rousseff, ocorrido em 17 de abril de 2016, e a chegada de Michel Temer à presidência, houve a revogação de todas as seleções do PMCMV (MINISTÉRIO DAS CIDADES, 2016), inclusive a da Ocupação Vito Giannotti.

Em 2017, surgiu a possibilidade de uma nova seleção para o benefício do PMCMV-Entidades. Em articulação com a Escola de Arquitetura e Urbanismo da Universidade Federal Fluminense (EAU-UFF), junto com o professor Ronaldo Brilhante, que tinha interesse em realizar um trabalho como exercício da disciplina de Projeto de Habitação Popular, os movimentos passaram a contar com as primeiras intenções projetuais.

Dessa maneira, foram realizadas as análises das possibilidades do prédio, que resultaram em várias combinações. Foram criadas três tipologias habitacionais para cada pavimento - térreo, pavimento tipo e cobertura - a serem apresentadas para que a opção que coubesse o maior número de unidades possíveis fosse escolhida. Baseado nessas combinações, com apoio do projeto participativo, foram elaboradas alternativas com números de unidades e formas de uso do espaço variadas, que resultaram em cerca de nove opções de tipologias habitacionais. A partir desses estudos, foi realizada uma assembleia com os moradores e os movimentos sociais vinculados para que fossem apresentadas as propos- tas e para que decidissem conjuntamente qual opção iriam escolher.

Entre o final de 2017 e o início de 2018, foi escolhida a alternativa que gerava vinte e oito unidades, opção que foi desenvolvida até a fase final do projeto, a ser apresentada para a Caixa Econômica Federal (CEF), quando houve a contratação do PMCMV-E.

\section{A Assessoria Técnica: Ocupação Vito Giannotti}

O projeto habitacional para a Ocupação Vito Giannotti se inicia diante de uma parceria entre movimentos sociais urbanos e o meio acadêmico. O envolvimento de instituições de ensino foi fundamental para o andamento e encaminhamento do projeto até a fase final, dada a demora demasiada para a conquista do benefício do Programa Entidades e do patrocínio para a equipe de Assessoria Técnica.

Com base na eleição de uma tipologia projetual pelos moradores e movimentos vinculados, foram realizadas assem-
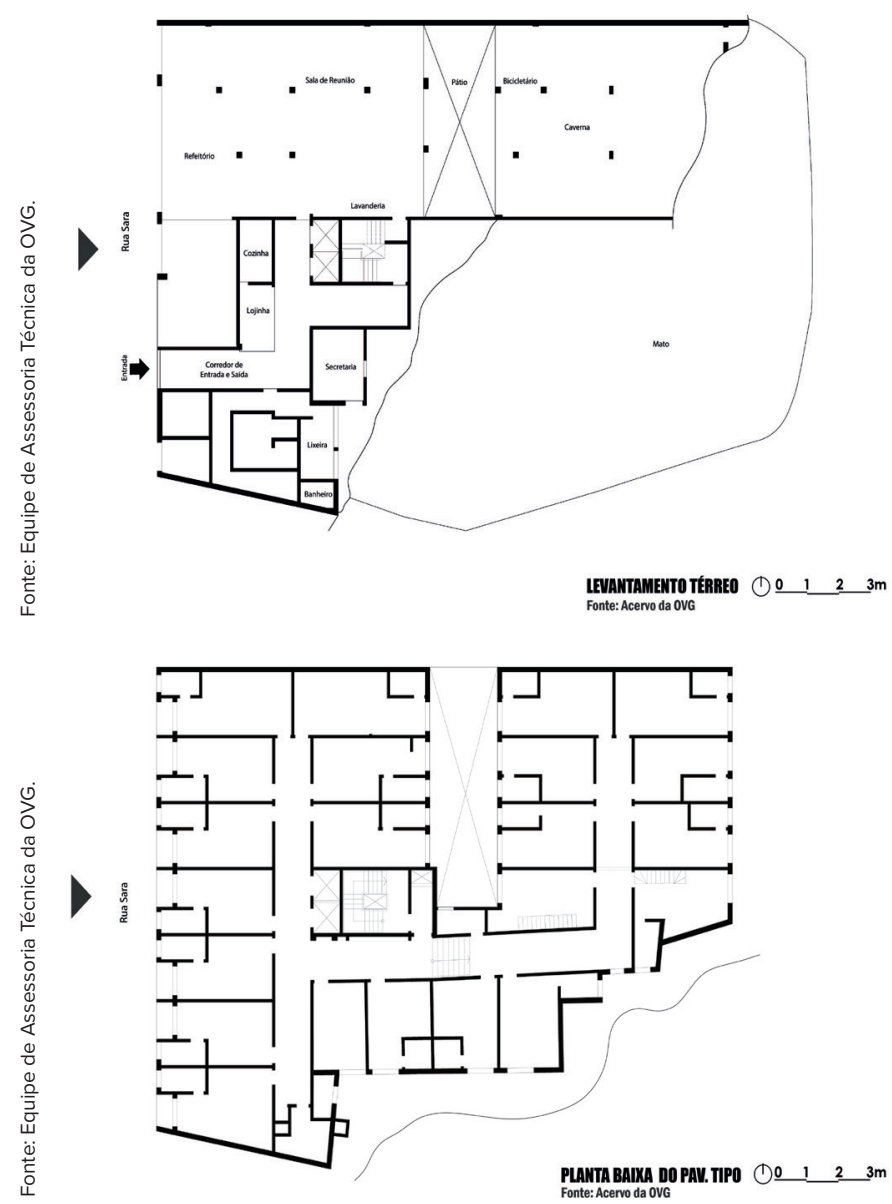

Figuras 5 e 6 (de cima para baixo). Levantamento da edificação realizado pelas atividades da EAU-UFF, 2017. 
bleias gerais com as famílias de forma que as ideias fossem compartilhadas. Para isso, fez-se necessário o uso de uma leitura menos técnica, através da transposição das plantas baixas da edificação em modelos físicos (maquetes), que permitisse total compreensão pelos moradores. As apresentações iniciais aconteceram sobre a projeção do edifício em planta baixa, com o intuito de que as famílias identificassem seus apartamentos, exercitando o reconhecimento e o entendimento projetual dos ocupantes.

Entretanto, com o decorrer de suas assembléias semanais, o movimento de luta por moradia identificou a falta de engajamento dos moradores, uma vez que era o mesmo grupo de pessoas que se envolviam nas reuniões. Notou-se um distanciamento, uma dificuldade de entendimento e pouca motivação das famílias em relação ao projeto habitacional. A equipe de assessoria técnica, junto aos movimentos, optou então pela realização de entrevistas individuais, que levaram a melhores resultados. Por esse processo, os moradores passaram a trazer questões que não haviam colocado em grupo, como a necessidade de haver espaços personalizados e da unidade comportar mais membros familiares.

Além disso, uma vez que a entrevista passou a ser realizada no apartamento de cada família, a equipe conseguiu identificar também como os moradores adaptaram suas próprias unidades. No momento das entrevistas, o edifício era disposto de 36 suítes distribuídas em planta-tipo e com cozinha coletiva. Nessa configuração, alguns moradores haviam conectado duas suítes para comportar mais membros familiares e, até mesmo, construído uma cozinha privativa dentro da unidade, no momento em que se instalaram no imóvel.

No final de 2018, a União Nacional por Moradia Popular (UNMP) redigiu uma proposta ao Conselho de Arquitetura e Urbanismo (CAU) a fim de adquirir o patrocínio para a assessoria técnica nas fases de anteprojeto e projeto executivo. A proposta foi aceita, contemplando com o patrocínio do CAU/ RJ a equipe de assessoria técnica, composta pela arquiteta Carolina Kroff, que havia participado das atividades realizadas pela EAU-UFF, Felipe Nin, arquiteto da União Nacional por Moradia Popular (UNMP), e estagiários bolsistas, estudantes da EAU-UFF. O patrocínio foi oficializado seguindo o edital 001/2018 (CHAMADA PÚBLICA 002/2018, 2018, on-line) e a equipe passou a desenvolver o projeto executivo do estudo iniciado pela EAU-UFF.
Mesmo com a posição do novo governo de tentar evitar a realização do projeto e a falta de estímulo à Assessoria Técnica, foram dados passos em favor da reconversão do edifício em moradia popular. A partir do edital do CAU, em 2018, a Assessoria Técnica surgiu como uma alternativa para dar continuidade ao trabalho iniciado no ambiente acadêmico, viabilizando recursos e fomentando a profissionalização dessa área, cada vez mais necessária. Logo depois, em 13 de junho de 2019, foi aprovada a Lei Municipal № 6.614 (RIO DE JANEIRO (RJ), 2019), de autoria da Vereadora Marielle Franco, instituindo a assessoria técnica gratuita para projeto e construção de Habitação de Interesse Social.

Art. 1으 O Município do Rio de Janeiro poderá prestar às famílias com renda mensal de até três salários mínimos, que possuam um único imóvel e residam no Município há, pelo menos, três anos, assistência técnica pública e gratuita para elaboração do projeto e a construção, reforma, ampliação e regularização fundiária de habitação de interesse social.

Parágrafo único. O direito à assistência técnica previsto no caput abrange todos os trabalhos de projeto, acompanhamento e execução de obras e serviços a cargo dos profissionais das áreas de arquitetura e urbanismo e engenharia necessários para a edificação, reforma, ampliação ou regularização fundiária da habitação.

\section{$[\ldots]$}

Art. 6o Com o objetivo de capacitar os profissionais e a comunidade usuária para a prestação dos serviços de assistência técnica previstos por esta Lei, poderão ser firmados convênios ou termos de parceria entre o ente público responsável e as entidades promotoras de programas de capacitação profissional, residência ou extensão universitária nas áreas de arquitetura e urbanismo e engenharia.

§ 1으 Os convênios ou termos de parceria previstos no caput deverão prever a busca de inovação tecnológica, a formulação de metodologias de caráter participativo e a democra- 
tização do conhecimento, promovendo um banco de experiências e a sua difusão. (RIO DE JANEIRO (RJ), 2019, p. 3)

\section{Etapas, processos e metodologia: Ocupação Vito Giannotti}

Tendo como parâmetro as atividades projetuais iniciadas pela EAU-UFF, é válido afirmar que a assessoria técnica foi, de fato, iniciada em 2017, antes mesmo da obtenção de patrocínio do CAU/RJ. Nesse processo, visitas, oficinas e trabalhos acadêmicos auxiliaram o desenvolvimento de estratégias para descobrir os desejos dos moradores para além da habitação, criando um programa de necessidades projetuais adaptado de forma participativa.

O programa de necessidades nasceu a partir da habitação, mas também considerou as possibilidades de se manterem os usos já existentes no edifício, tais como a lavanderia e a cozinha coletiva. Essas decisões foram tomadas em assembleia, porém, com as exigências da Caixa Econômica Federal, algumas solicitações - como a cozinha coletiva perderam seu caráter original. O edital da Caixa Econômica Federal exigia que as unidades possuíssem cozinha e área de serviço previstos em projeto (MINISTÉRIO DAS CIDADES, 2018a). Mesmo assim, a cozinha coletiva foi incorporada ao programa de necessidades, deixando de servir de uso diário aos moradores e passando a ser destinada a eventos do coletivo e da comunidade Morro do Pinto.

Além disso, optou-se por manter o alojamento existente para que a Ocupação pudesse receber movimentos de fora do Rio de Janeiro. Desde o início, foi solicitado pelos moradores que o projeto também comportasse um local para reuniões, maior do que o existente. Assim, o pátio da edificação original foi adaptado e transformado em um ponto central para os movimentos do Centro do Rio de Janeiro.

O desejo dos moradores era de que o programa de necessidades comportasse uma parte das atividades destinadas à comunidade Morro do Pinto e movimentos sociais, a outra parte sendo destinada aos moradores da OVG. Nessa etapa, os moradores também apontaram o desejo por espaços para geração de renda. Porém, com o tempo, a prioridade das habitações foi tomando espaço e tais espaços foram eliminados do programa de necessidades por decisões em assembleias, favorecendo a ampliação de área dos apartamentos.
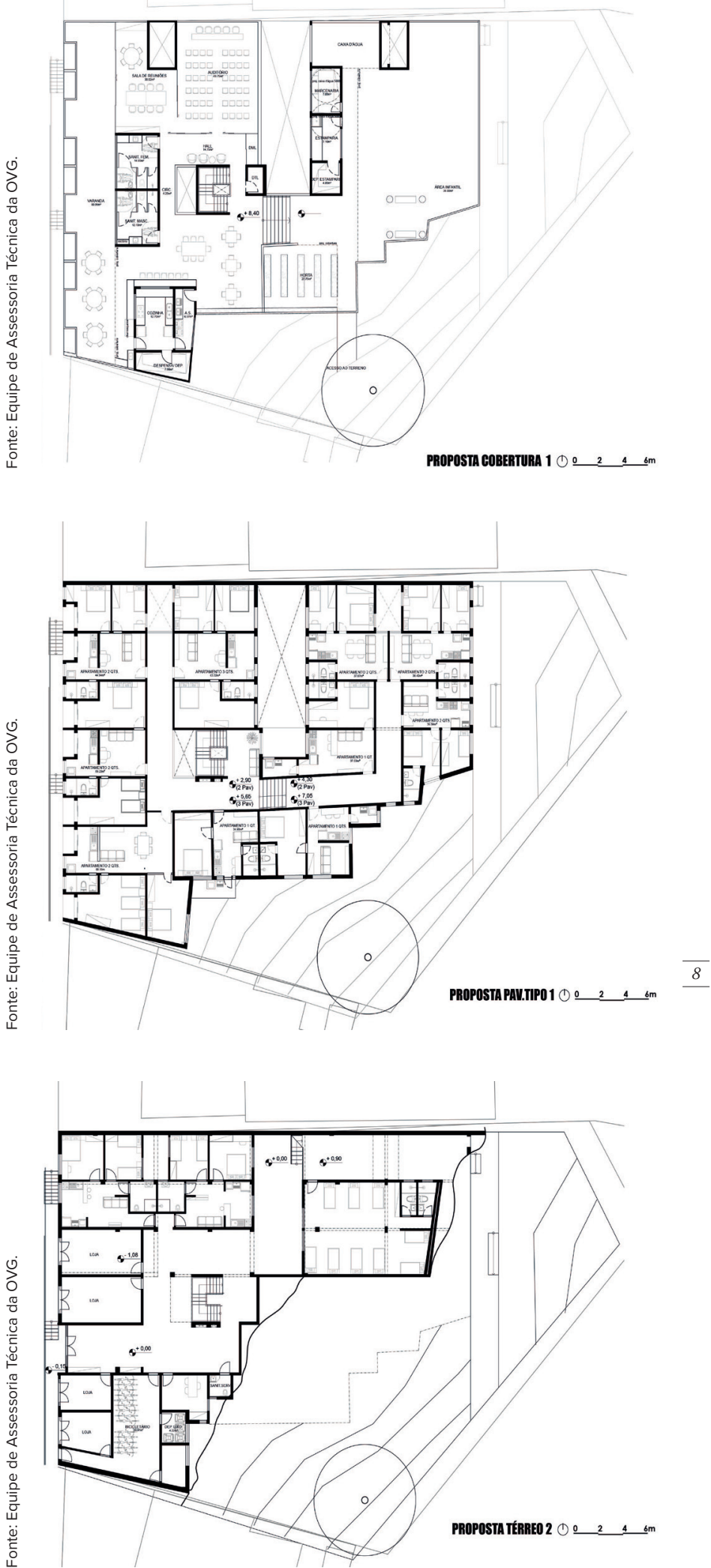

Figuras 7, 8 e 9 (de cima para baixo). Propostas elaboradas pelas atividades da EAU-UFF, 2017. 


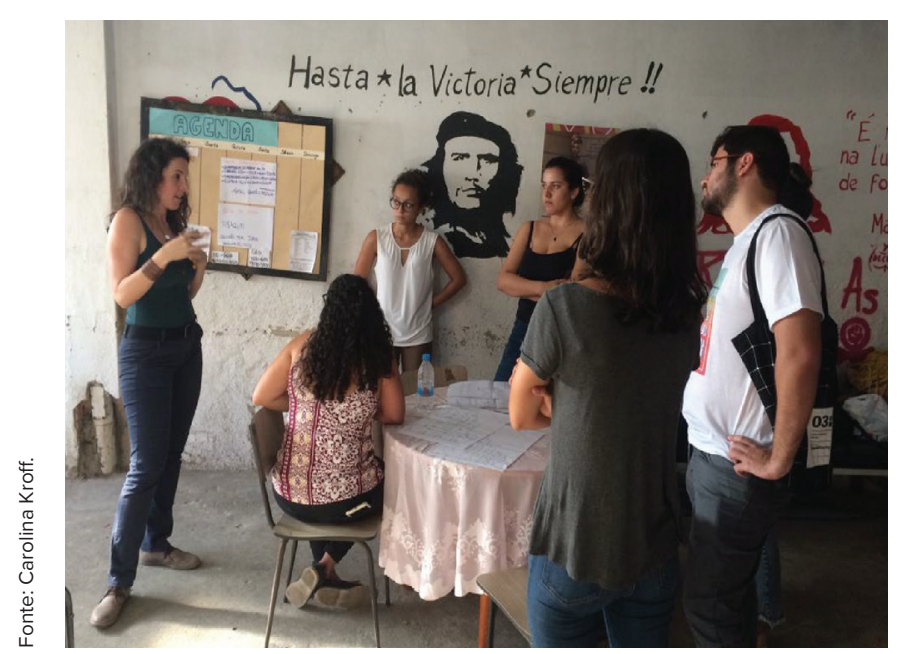

Figura 10. Reunião entre a engenheira e os estudantes de arquitetura para o mapeamento de patologias do edifício, 2019.

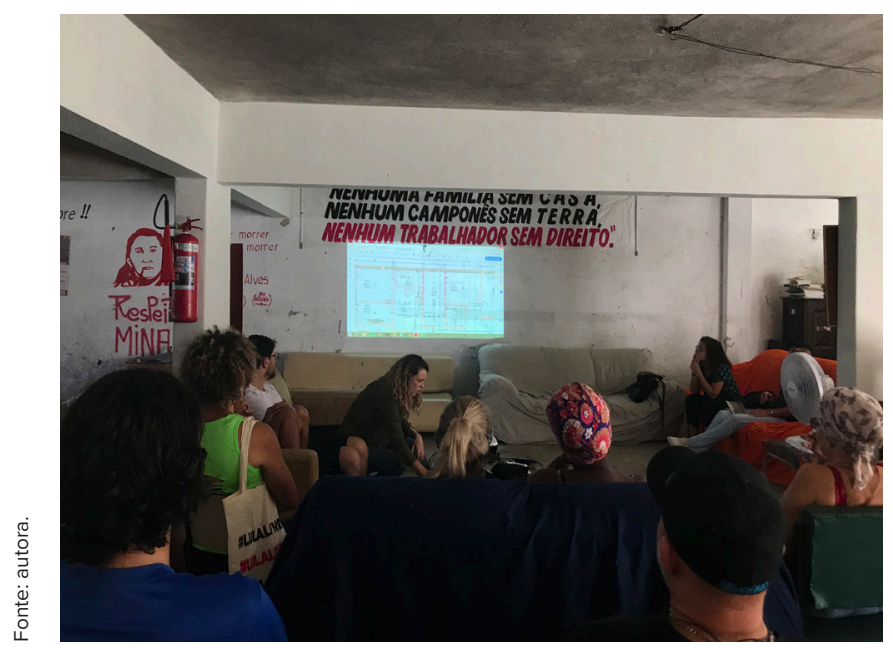

Figura 11. Assembléia para a discussão de projeto do PMCMVEntidades entre moradores e a equipe de Assessoria Técnica, 2019.

Durante a assessoria técnica, foi possível que a equipe identificasse métodos para a elaboração do projeto participativo baseado em experimentações em oficinas de projeto com os residentes, verificando a eficácia das atividades desenvolvidas com a autogestão. Assim, como metodologia projetual, a arquiteta coordenadora da equipe de assessoria técnica, Carolina Kroff, procurava apresentar as propostas durante as assembleias com os moradores, demonstrando pontos positivos na solução de cada opção demonstrada. Um exemplo disso foi a solução de incluir novos prismas, apresentada como artifício para redução na conta de luz do edifício e para a melhoria da ventilação e da luz natural no espaço.
Houve ainda problemas relacionados aos recursos da assessoria, que interferiram na metodologia utilizada. A falta de verba para as apresentações e elaboração de maquetes acabaram dificultando o entendimento das famílias sobre as soluções projetuais propostas. Com isso, os recursos para modelos físicos (maquetes) e apresentações acabaram partindo da própria arquiteta ou de doações de materiais da EAU-UFF.

Mesmo com o Programa MCMV-Entidades e o patrocínio da Assessoria Técnica pelo CAU/RJ, foi possível notar que ainda se precisaria de mais estímulos para os recursos necessários para a realização de oficinas participativas. Os baixos orçamentos dificultam a qualidade do desenvolvimento projetual, sendo necessário a ajuda de profissionais que trabalham por iniciativa própria e voluntários, o que precariza a mão de obra e o trabalho apresentado.

Com a finalidade de avançar mais o projeto para além do trabalho desenvolvido pela EAU-UFF para o estudo preliminar, a Ocupação Vito Giannotti se articulou posteriormente com o escritório modelo de arquitetura da Universidade Federal Rural do Rio de Janeiro (UFRRJ), em 2019. O objetivo era a realização de oficinas para se pensar de forma participativa o paisagismo e a criação de uma horta comunitária dentro da ocupação, independentemente do PMCMV-Entidades. As oficinas foram divididas em encontros organizados entre a equipe de assessoria técnica e os moradores. Dessa forma, foram realizados mutirões de limpeza da área a ser projetada e oficinas para se pensar o projeto participativo e entender as necessidades das famílias para a criação de um programa projetual.

\section{A horta comunitária e o projeto participativo: Ocupação Vito Giannotti}

A concepção da horta definiu que seria um espaço interativo para as crianças e para os adultos interessados em cuidar do espaço, sem estabelecer obrigatoriedades. Os moradores da OVG propuseram também que a horta fosse um espaço aberto à comunidade Morro do Pinto, visto que, segundo eles, esta era uma carência do bairro: "Antes isso aqui era tudo lixo, se a gente abrir, os vizinhos vão poder sentir a agradabilidade do projeto e vão perceber as transformações positivas que a gente fez nesse espaço aqui” (Informação verbal) ${ }^{6}$.

Por meio do projeto participativo durante as oficinas, foi definido também que a horta seria usada para consumo próprio e até para geração de renda de alguns moradores.

Revista online do Departamento de Arquitetura e Urbanismo da Pontifícia Universidade Católica do Rio de Janeiro - PUC-Rio, Brasil Ano 8 - N응 - ISSN 2446-7340 
Nesse momento, foram definidas as espécies de plantio: verduras, legumes, árvores frutíferas, temperos e ervas medicinais. Segundo os moradores, a horta seria uma necessidade imediata, uma vez que alguns indivíduos não podiam arcar financeiramente com uma alimentação mais saudável, além do edifício carecer de espaços ao ar livre para que as crianças pudessem brincar.

Há poucos espaços para as crianças, ou elas estão no térreo, mas o pessoal da portaria reclama, ou nos corredores, mas os moradores dos apartamentos reclamam, e o terraço é trancado, é proibido por questão de segurança. Então, existe a necessidade de um espaço para eles brincarem, falarem alto, correrem e jogarem bola com segurança. (Informação

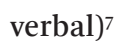

A oficina propiciou a troca de ideias fundamentadas nas referências apresentadas pelos estudantes e as demandas levantadas pelos moradores. Com isso, definiu-se um programa projetual para o espaço da horta, com uma área livre para as crianças, horta vertical hidropônica e plantio de vegetais para consumo próprio, além da perspectiva de possível geração de renda.

Com a demora para vencer as burocracias do PMCMV-Entidades, a horta se tornou uma iniciativa política e necessária à resolução de questões imediatas que careciam de soluções e não poderiam aguardar o tempo burocrático do PMCMV-Entidades.

\section{Considerações}

A experiência voluntária no acompanhamento dos trabalhos de Assessoria Técnica na Ocupação Vito Giannotti comprovaram a importância dos instrumentos da assessoria técnica para realização de um projeto participativo, a fim de propor como reflexão a necessidade de profissionalizá-la e aproximá-la do meio acadêmico. Desse modo, pode-se considerar a importância da formação de profissionais do campo da arquitetura e do urbanismo capazes de mediar projetos participativos de maneira horizontal, que contribuam para criação de espaços pensados de forma participativa para a cidade. Diante da autogestão, estudantes e profissionais de arquitetura podem reavaliar suas práticas, adaptando-se, por exemplo, à escuta ativa, ${ }^{8}$ e assim aprender com os próprios usuários dos espaços que projetam.

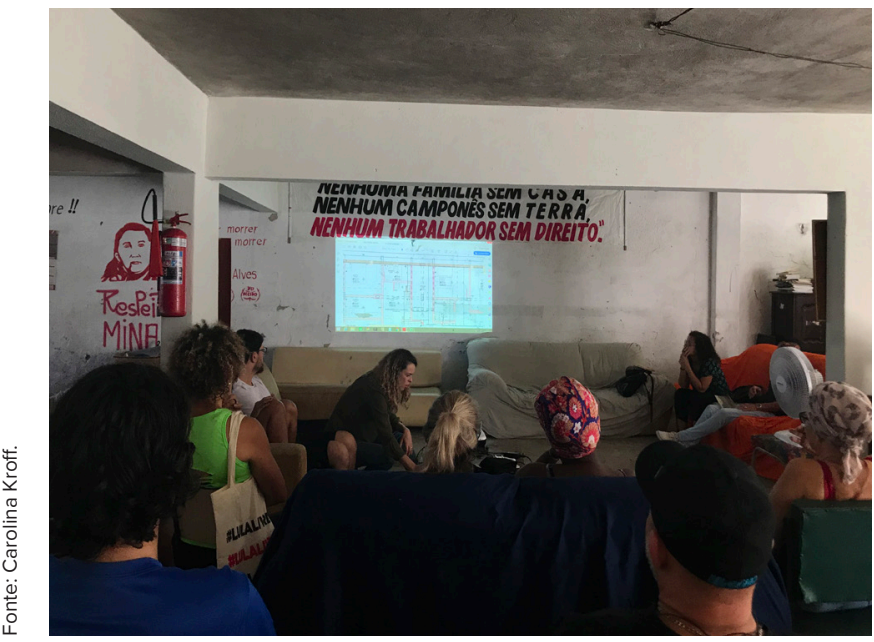

Figura 12. Oficina de paisagismo, 2019. Atividade para discutir os espaços e as espécies de plantio da horta comunitária e articular o mutirão de limpeza.
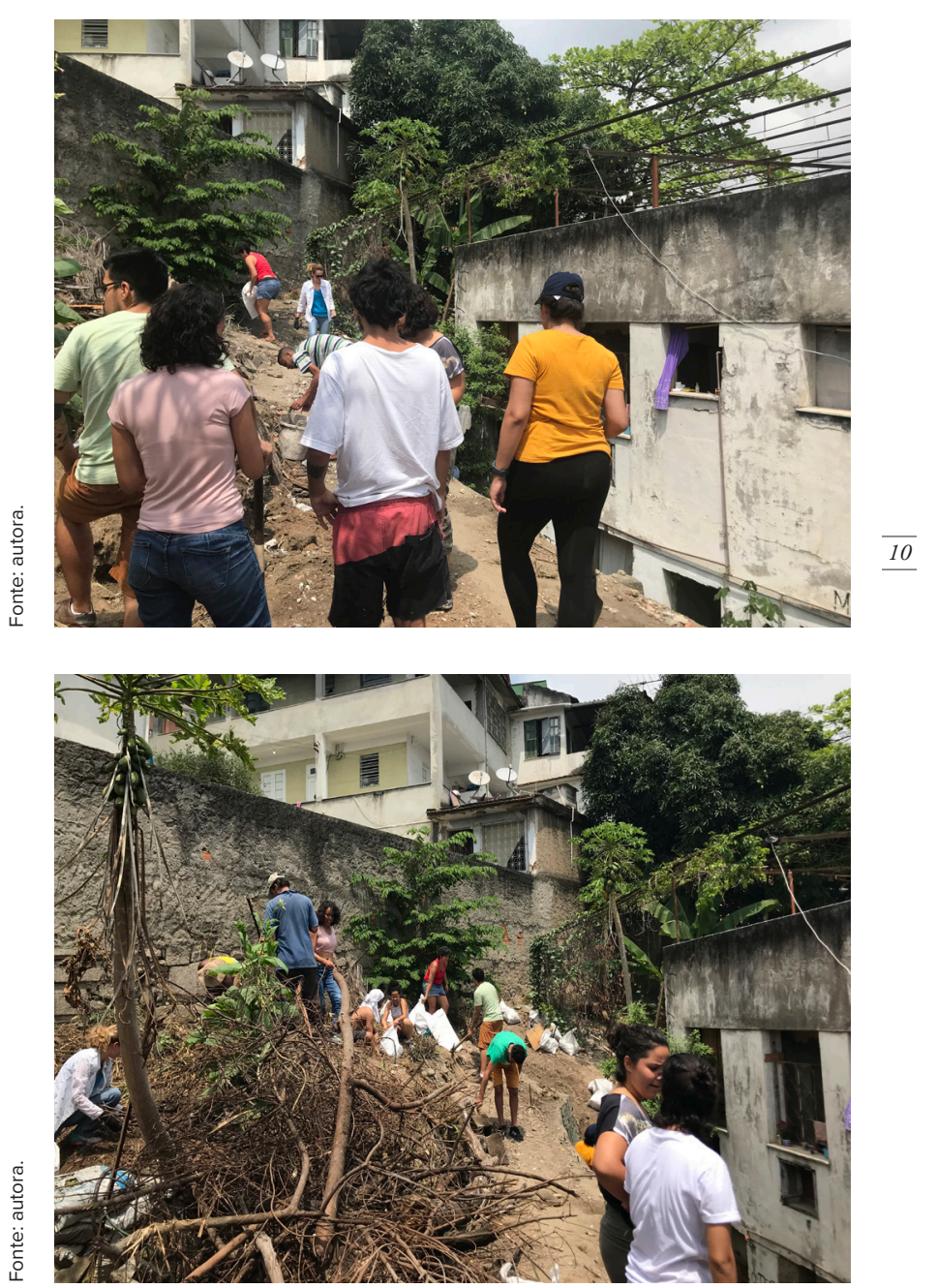

Figuras 13 e 14 (de baixo para cima). Oficina de paisagismo, 2019. Atividade para discutir os espaços e as espécies de plantio da horta comunitária e articular o mutirão de limpeza. 


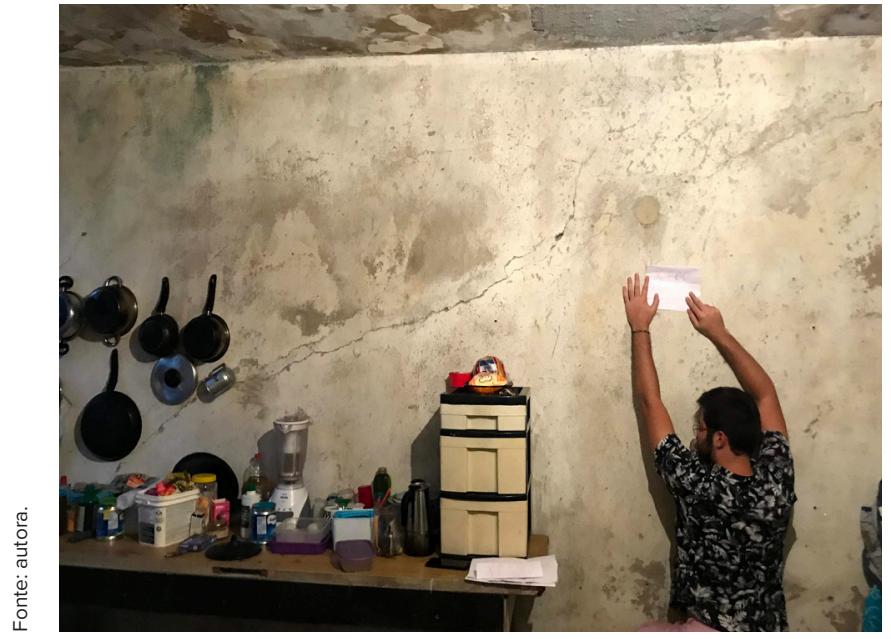

Figura 15. Mapeamento de patologias no interior dos apartamentos da ocupação, 2019. Atividade realizada pelos estudantes de arquitetura em conjunto com a engenheira e a arquiteta da equipe de Assessoria Técnica.

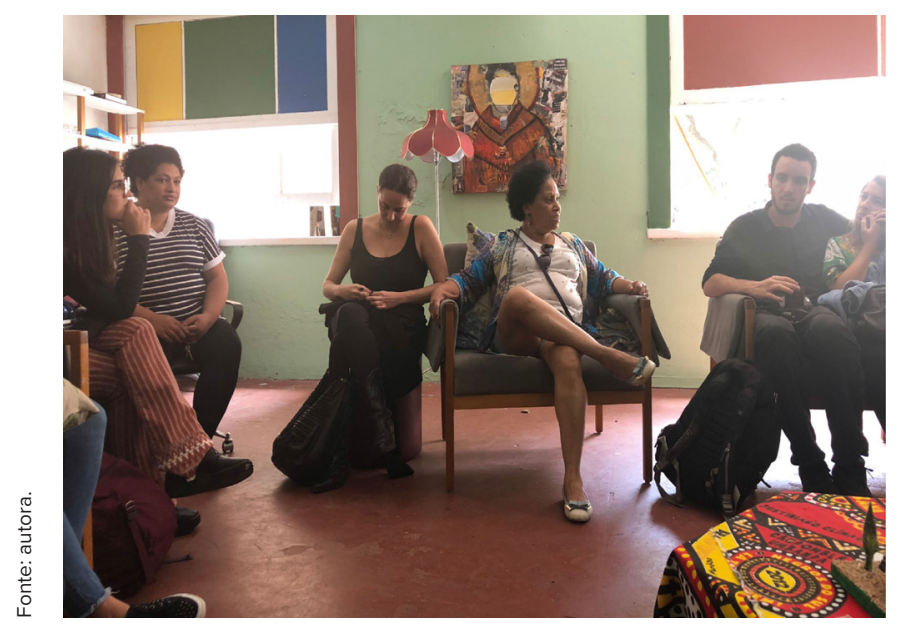

Figura 16. Entrevista com Carmen Silva, militante pelo movimento de luta pela moradia, na Ocupação 9 de Julho, em São Paulo, 2018. Atividade realizada durante a disciplina eletiva de Habitação de Interesse Social do Departamento de Arquitetura da PUC-Rio.

Durante as vivências entre a equipe de assessoria técnica, foi possível compreender a ineficácia do PMCMV tradicional, bem como a importância de ter um olhar atento, individual e sensível para cada família que utilizará o espaço a ser projetado. Ao longo das atividades de assessoria técnica na OVG, foram atendidas famílias com 5 integrantes e pessoas morando sozinhas em unidades de mesma metragem, cada qual com necessidades particulares e específicas para a habitação.

O diferencial do PMCMV-Entidades é operar com a autogestão como peça central para o desenvolvimento e para a tomada de decisões do projeto arquitetônico, enquanto o arquiteto e urbanista atua como mediador e executor. Dessa forma, surgem projetos mais eficazes, personalizados, com identidade, obtendo um resultado mais satisfatório para as famílias beneficiadas.

De acordo com Silke Kapp (2018), a assessoria técnica precisa ultrapassar as noções de cliente, usuário e beneficiário, uma vez que, há tempos, a cidade é projetada pelos próprios moradores, vide a autoconstrução em favelas. Logo, não cabe ao arquiteto ser o impositor de ideias, uma vez que o projeto participativo contribui positivamente para o desenvolvimento da cidade, na medida em que é capaz de ressignificar funcionalmente uma área que foi pensada pelos seus próprios usuários.

Analogamente, os grupos assessorados se submetiam aos arquitetos em troca de representação junto a prefeituras, bancos e outras instâncias com as quais não negociam sozinhos, seja por interdições objetivas ou constrangimentos subjetivos. De fato, essa é uma das razões mais comuns de grupos procurarem a assessoria técnica mesmo quando têm convicção de que não precisariam dela para equacionar espaços e construções. Menos mal se todos estivessem conscientes disso e a assessoria assumisse função advocatícia sem impor serviços técnicos não de mandados. (KAPP, 2018, p. 5)

Conclui-se que os cursos de arquitetura e urbanismo de instituições de ensino superior podem tratar do tema como complementação à formação teórica de futuros arquitetos. Com supervisão, é possível se aproximar da realidade e ter a oportunidade de vivenciar o campo e discutir o que aprenderam no ambiente acadêmico. Assim, estudantes podem desenvolver a capacidade de mediação e treinar o momento de propor e de escutar, atuando horizontalmente em projetos participativos, como o exemplo de prática nas escolas de arquitetura da UFF e da UFRRJ.

Com base no trabalho empírico, é válido afirmar que, para avançarmos nos trabalhos de Assessoria Técnica para reconversão de imóveis abandonados em moradia, é urgente capacitar profissionais. Isso pode ser feito desde a atuação das escolas de arquitetura no ensino de teorias, métodos e práticas mais próximas à realidade e às demandas reais desse problema. Evidencia-se a necessidade de trazer expe-

Revista online do Departamento de Arquitetura e Urbanismo da Pontifícia Universidade Católica do Rio de Janeiro - PUC-Rio, Brasil Ano 8 - N응 - ISSN 2446-7340 
riências mais factíveis para o ambiente acadêmico, que correspondam à realidade do déficit habitacional brasileiro e a readequação de imóveis vacantes frente à demanda habitacional, ao invés de formar profissionais que foram ensinados apenas a projetar novos espaços com novos usos, desconsiderando a readequação de espaços pré-existentes. Dessa forma, tais experiências podem contribuir para a formação de estudantes com habilidades para assessoramento técnico - área que vem sendo formalizada - , colaborando de forma real e concreta, com a alta demanda de apoio técnico às famílias em situação de emergência sócio-habitacional.

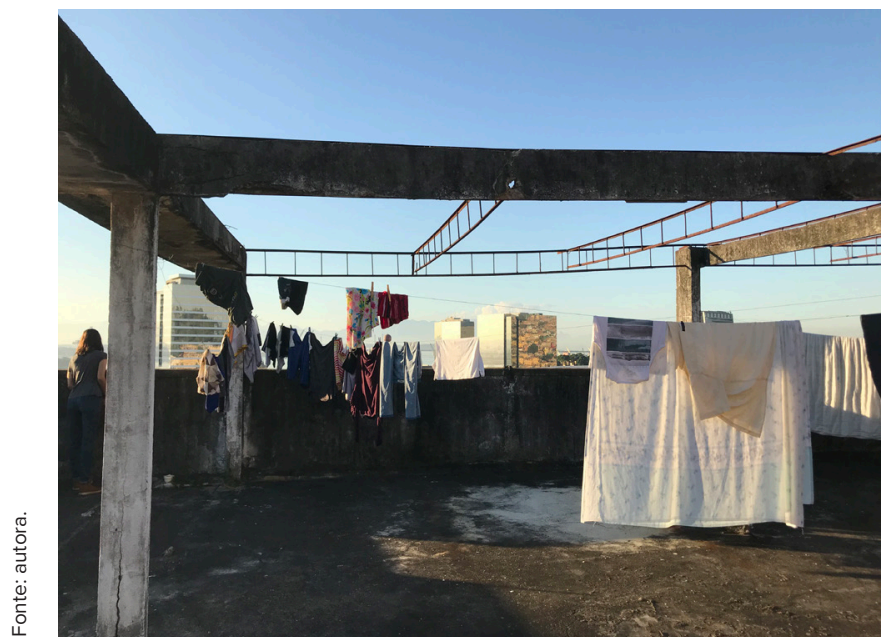

Figura 17. Terraço do edifício da Ocupação Vito Giannotti, 2019. No horizonte é possível notar o processo de gentrificação da Zona Portuária em contraste com a demanda por moradia na área central da cidade.

\section{Notas de fim:}

1. A Operação Urbana Consorciada Água Espraiada (OUCAE) foi a primeira Operação Urbana a utilizar os dispositivos do Estatuto da Cidade (Lei Federal no 10.257/2001) e, por conta disso, a primeira Consorciada aprovada (PREFEITURA DA CIDADE DE SÃO PAULO, on-line). Sobre a criação da OUCAE, ver: São Paulo (SP) (2001a). Sobre as alterações na OUCAE, ver: São Paulo (SP) (2001b, 2018). Sobre a regulamentação da OUCAE, ver: São Paulo (SP) (2012).

2. O maior cortiço do Rio de Janeiro, conhecido como Cabeça de Porco, era localizado na Rua Barão de São Felix, próximo ao morro da Providência, e abrigava entre duas mil e quatro mil pessoas.

3. O Programa foi criado durante o segundo mandato do presidente Luís Inácio Lula da Silva (2007-2010) com o objetivo de produzir um milhão de moradias entre 2010 a $2011 \mathrm{e}$, por isso, foi considerado o primeiro grande programa público de provisão habitacional após a extinção do Banco Nacional de Habitação (BNH), na década de 1980.
4. No Rio de Janeiro, a maior concentração dos condomínios foi na zona oeste da cidade. Em sua maioria, são condomínios da Faixa 1, que, de acordo com as condições da Caixa Econômica Federal para 2021, atende a famílias com renda mensal de até $\mathrm{R} \$ 1.800$,00 (GOVERNO FEDERAL, on-line).

5. É importante ressaltar, que nesse momento, o contexto era de implementação do Plano Estratégico 2016, que tinha por objetivo a preparação da cidade do Rio de Janeiro para a recepção dos eventos Olímpicos, incluindo a realização de obras para melhoria da infraestrutura, serviços, moradia e lazer na região. Com isso, o Planejamento Estratégico acabou criando uma ideia de cidade moderna e competitiva, uma vez que os projetos propostos acompanharam uma propaganda justificada como essencial para a cidade, com o objetivo de atrair investimentos internacionais e inseri-la no contexto global. Assim, por exemplo, fizeram-se a requalificação da Zona Portuária, a implementação de vários corredores e as remoções e intervenções urbanísticas em favelas por meio de projetos como o Morar Carioca.

6. Fala de um dos moradores durante a oficina de projeto para a horta comunitária, Ocupação Vito Giannotti, em 6 out. 2019.

7. Fala de um dos moradores durante a oficina de projeto para a horta comunitária, Ocupação Vito Giannotti, em 6 out. 2019..

8. Nos processos empíricos deste trabalho, esse termo foi utilizado pelas minorias sociais para designar a escuta a estes grupos com atenção e, ainda, ao ceder espaço de fala aos que, historicamente, nunca foram ouvidos.

\section{Referências Bibliográficas:}

ABREU, Maurício de A. Evolução Urbana do Rio de Janeiro. 4. Ed. Rio de Janeiro: Instituto Pereira Passos, 2013.

BASTOS, Thiago. Autogestão e a luta pela desmercantilização da moradia: Uma experiência no Rio de Janeiro. Rio de Janeiro: Observatório de Metrópoles, 2019.

BIANCA.LOBIANCO. Cinco mil imóveis estão abandonados no Rio: 300 deles somente no Centro. O Dia, 6 set. 2014. Disponível em: https://odia.ig.com.br/noticia/rio-de-janeiro/2014-09-07/cinco-mil -imoveis-estao-abandonados-no-rio-30o-deles-somente-no-centro. html. Acesso em: 5, set. 2019.

BRASIL. Resolução no 21 de 16 de agosto de 2007 / INSS - Instituto Nacional do Seguro Social. Autoriza alienação de imóveis ao Fundo de Arrendamento Residencial-FAR, representado pela Caixa Econômica Federal, para atendimento ao Programa de Arrendamento Residencial-PAR. Diário Oficial da União, 17 ago. 2006. Disponível em: https://www.diariodasleis.com.br/busca/exibelink.php?numlink =1-76-34-2007-08-16-21. Acesso em: 20, set. 2021.

CAIXA ECONÔMICA FEDERAL. Programa Minha Casa Minha Vida: Entidades - Recursos FDS. Documento on-line. Disponível em: https://www.caixa.gov.br/Downloads/habitacao-minha-casaminha-vida/MANUAL_MCMV_ENTIDADES.pdf. Acesso em: 21, nov. 2021.

CHAMADA PÚBLICA 002/2018. Conselho de Arquitetura e Urbanismo do Rio de Janeiro, 2018. Edital on-line. Disponível em: http://www.caurj .gov.br/wp-content/uploads/2018/08/Edital-ATHIS.pdf. Acesso em: 18, set. 2021. 
CONSELHO CURADOR DO FUNDO DE DESENVOLVIMENTO SOCIAL. Resolução № 141, de 10 de junho de 2009. Regulamenta a utilização de recursos da União previstos no Art. 17 da MP no 459, de 25 de março de 2009, e no Art. 16 do Decreto no 6.819 de 13 de abril de 2009, criando o Programa Habitacional Popular - Entidades - Minha Casa, Minha Vida voltado ao atendimento das necessidades habitacionais de famílias de baixa renda, organizadas em cooperativas habitacionais ou mistas, associações e demais entidades privadas sem fins lucrativos. Diário Oficial da União: seção 1, Brasília, DF, n. 111, p. 79-80, 15 jun. 2009.

FUNDAÇÃO JOÃO PINHEIRO: Governo de Minas Gerais. Estatística e Informações: demografia e indicadores sociais - Déficit habitacional no Brasil: 2015. Belo Horizonte: Fundação João Pinheiro, 2018. Disponível em: http://www.bibliotecadigital.mg.gov.br/consulta /consultaDetalheDocumento.php?iCodDocumento $=76871 \mathrm{\#}$. Acesso em: 22, nov. 2021.

GOVERNO FEDERAL. Caixa Econômica Federal. Minha Casa Minha Vida - Habitação Urbana. Disponível em: https://www.caixa.gov.br /voce/habitacao/minha-casa-minha-vida/urbana/Paginas/default.aspx. Acesso em: 21, nov. 2021.

KAPP, Silke. Grupos sócio-espaciais ou a quem serve a assessoria técnica. Revista Brasileira de Estudos Urbanos Regionais, São Paulo, v. 20, n. 2, p. 221-236, maio/ago. 2018. Disponível em: https://rbeur.anpur.org.br /rbeur/ article/view/5605/pdf. Acesso em: 24, out. 2019.

LEI INSTITUI A ASSISTÊNCIA TÉCNICA para habitação de interesse social na cidade do Rio de Janeiro. Conselho de Arquitetura e Urbanismo do Rio de Janeiro, Rio de Janeiro, 14, jun. 2019. Disponível em: https://www.caurj.gov.br/lei-institui-a-assistencia-tecnica-para-habitacao -de-interesse-social-na-cidade-do-rio-de-janeiro/. Acesso em: 05, dez. 2021.

MINISTÉRIO DAS CIDADES. Portaria no 163 , de 6 de maio de 2016. Institui o Sistema Nacional de Cadastro Habitacional (SNCH) e aprova o Manual de Instruções para Seleção de Beneficiários do Programa Nacional de Habitação Urbana (PNHU), no âmbito do Programa Minha Casa, Minha Vida (PMCMV). Diário Oficial da União: seção 1, Brasília, DF, n. 87, p. 117, 9 mai. 2016.

MINISTÉRIO DAS CIDADES. Portaria no 66o, de 14 de novembro de 2018. Dispõe sobre as diretrizes para a elaboração de projetos e estabelece as especificações técnicas mínimas da unidade habitacional e as especificações urbanísticas dos empreendimentos destinados à aquisição e alienação com recursos advindos da integralização de cotas no Fundo de Arrendamento Residencial - FAR, e contratação de operações com recursos transferidos ao Fundo de Desenvolvimento Social - FDS, no âmbito do Programa Minha Casa, Minha Vida - PMCMV. Diário Oficial da União: seção 1, Brasília, DF, n. 220, p. 105, 16 nov. 2018a.

MINISTÉRIO DAS CIDADES. Portaria no 367, de 07 de junho de 2018. Regulamenta o Processo de seleção de propostas para participação no Programa Minha Casa, Minha Vida - Entidades - PMCMV-E. Diário Oficial da União: seção 1, Brasília, DF, n. 109, p. 165, 08 jun. 2018 b.

PALlASMAA, Juhani. Habitar. Tradução: Alexandre Salvaterra. São Paulo: Gustavo Gili, 2017.

PREFEITURA DA CIDADE DE SÃO PAULO. Gestão Urbana SP. Operação Urbana Consorciada Água Espraiada. Disponível em: https:// gestaourbana.prefeitura.sp.gov.br/estruturacao-territorial/operacoes -urbanas/oucae/. Acesso em: 21, nov. 2021.
RIO DE JANEIRO (RJ). Lei Municipal no 6.614, de 13 de junho de 2019. Institui a assistência técnica pública e gratuita para projeto e construção de habitação de interesse social para as famílias de baixa renda e dá outras providências. Diário Oficial do Rio de Janeiro, Rio de Janeiro, ano 33, n. 62, p. 3, 14 jun. 2019. Disponível em: https:// doweb.rio.rj.gov.br/portal/visualizacoes/pdf/4171/\#/p:3/e:4171. Acesso em: 5, dez. 2021.

ROLNIK, Raquel. Guerra dos Lugares: A colonização da terra e da moradia na era das finanças. São Paulo: Boi Tempo, 2015.

SÃO PAULO (SP). Lei № 13.260 de 28 De Dezembro de 2001. Estabelece diretrizes urbanísticas para a área de influência da atual Avenida Água Espraiada, de interligação entre a Avenida Nações Unidas (Marginal do Rio Pinheiros) e a Rodovia dos Imigrantes, cria incentivos por meio de instrumentos de política urbana para sua implantação, institui o Grupo de Gestão, e dá outras providências. São Paulo: Legislação Municipal de São Paulo, 2001a.

SÃO PAULO (SP). Lei № 15.416 De 22 de Julho de 2011. Altera os arts. $3^{\circ}, 22,25$ e 28 da Lei № 13.260 , de 28 de dezembro de 2001 , que aprovou a Operação Urbana Consorciada Água Espraiada. São Paulo: Legislação Municipal de São Paulo, 2001b.

SÃO PAULO (SP). Decreto No 53.364 de 17 de Agosto De 2012. Confere nova regulamentação à Lei № $\mathbf{1 3 . 2 6 0}$, de 28 de dezembro de $\mathbf{2 0 0 1}$, que aprova a Operação Urbana Consorciada Água Espraiada, com as alterações introduzidas pelas Leis $\mathrm{n} \underline{\mathbf{0}} \mathbf{1 5 . 4 1 6}$, de 22 de julho de 2011, e no 15.519 , de 29 de dezembro de 2011; revoga os Decretos no 44.845 , de 14 de junho de $2004, n \div 47 \cdot 316$, de 26 de maio de 2006 , $\mathrm{n}$ o 51.277 , de 4 de fevereiro de $2010, \mathrm{n}$ o 51.914 , de 9 de novembro de 2010, n⿳⺈ 52.879, de 27 de dezembro de 2011, bem como os artigos 77 a 81 do Decreto no 50.995, de 16 de novembro de 2009. São Paulo: Legislação Municipal de São Paulo, 2012.

SÃO PAULO (SP). Lei № 16.975 De 3 de Setembro de 2018. Aprova o Plano Urbanístico Complementar do Setor Chucri Zaidan da Operação Urbana Consorciada Água Espraiada, nos Distritos de Santo Amaro e Itaim Bibi, altera a Lei № $\mathbf{1 3 . 2 6 0 , ~ d e ~} 28$ de dezembro de 2001, e dá outras providências. São Paulo: Legislação Municipal de São Paulo, 2018.

SILVA FILHO, Ernesto Batista da. Empreendimentos do Programa Minha Casa, Minha Vida. Empreendimentos pertencentes a Carteira do PAC. Data de referência março/2012. - escala 1:1.000.00o. Sistema de referência: SIRGAS200o. Dados cartográficos. Portal Brasileiro de Dados Abertos, 19 abr. 2015. Última atualização: 12 jun. 2018. Disponível em: https://dados.gov.br/dataset/mpog_mcmv. Acesso em: 20, mar. 2019.

VOGEL, Arno; MELLO, Marco Antônio. Lições da Rua: O que um racionalista pode aprender no Catumbi. Arquitetura Revista, Rio de Janeiro, v. 1, n. 1, p. 67-79, 1983. 